\title{
Incidence of hyperoxia in trauma patients receiving pre-hospital emergency anaesthesia: results of a 5-year retrospective analysis
}

\author{
P. Leitch ${ }^{1}$, A. L. Hudson 1,2, J. E. Griggs ${ }^{2,3^{*}}$ (D) R. Stolmeijer ${ }^{4}$, R. M. Lyon ${ }^{2,3}$ and E. ter Avest ${ }^{2,4}$ on behalf of Air \\ Ambulance Kent Surrey Sussex
}

\begin{abstract}
Background: Previous studies have demonstrated an association between hyperoxia and increased mortality in various patient groups. Critically unwell and injured patients are routinely given high concentration oxygen in the prehospital phase of care. We aim to investigate the incidence of hyperoxia in major trauma patients receiving pre-hospital emergency anesthesia (PHEA) in the pre-hospital setting and determine factors that may help guide clinicians with pre-hospital oxygen administration in these patients.
\end{abstract}

Methods: A retrospective cohort study was performed of all patients who received PHEA by a single helicopter emergency medical service (HEMS) between 1 October 2014 and 1 May 2019 and who were subsequently transferred to one major trauma centre (MTC). Patient and treatment factors were collected from the electronic patient records of the HEMS service and the MTC. Hyperoxia was defined as a $\mathrm{PaO}_{2}>16 \mathrm{kPA}$ on the first arterial blood gas analysis upon arrival in the MTC.

Results: On arrival in the MTC, the majority of the patients (90/147,61.2\%) had severe hyperoxia, whereas 30 patients (20.4\%) had mild hyperoxia and 26 patients (19.7\%) had normoxia. Only 1 patient (0.7\%) had hypoxia. The median $\mathrm{PaO}_{2}$ on the first arterial blood gas analysis (ABGA) after HEMS handover was 36.7 [IQR 18.5-52.2] kPa, with a range of 7.0-86.0 kPa. $\mathrm{SpO}_{2}$ pulse oximetry readings before handover were independently associated with the presence of hyperoxia. An $\mathrm{SpO}_{2} \geq 97 \%$ was associated with a significantly increased odds of hyperoxia (OR 3.99 [1.58-10.08]), and had a sensitivity of $86.7 \%$ [79.1-92.4], a specificity of 37.9\% [20.7-57.8], a positive predictive value of 84.5\% [70.2-87.9] and a negative predictive value of $42.3 \%$ [27.4-58.7] for the presence of hyperoxemia.

Conclusion: Trauma patients who have undergone PHEA often have profound hyperoxemia upon arrival at hospital. In the pre-hospital setting, where arterial blood gas analysis is not readily available a titrated approach to oxygen therapy should be considered to reduce the incidence of potentially harmful tissue hyperoxia.

Keywords: Hyperoxia, Hyperoxemia, Ventilation, Trauma, Emergency medical services, Oxygen therapy, Pre-hospital anesthesia

*Correspondence: JoG@aakss.org.uk

2 Air Ambulance Kent Surrey and Sussex, Hanger 10 Redhill Aerodrome, Redhill RH1 5YP, UK

Full list of author information is available at the end of the article

\section{Background}

Major trauma results in 20,000 cases in England each year [1]. Helicopter emergency medical services (HEMS) are frequently dispatched to patients after major trauma, since they can deliver specific, advanced clinical interventions that land ambulance crews are unable to original author(s) and the source, provide a link to the Creative Commons licence, and indicate if changes were made. The images or other third party material in this article are included in the article's Creative Commons licence, unless indicated otherwise in a credit line to the material. If material is not included in the article's Creative Commons licence and your intended use is not permitted by statutory regulation or exceeds the permitted use, you will need to obtain permission directly from the copyright holder. To view a copy of this licence, visit http://creativecommons.org/licenses/by/4.0/. The Creative Commons Public Domain Dedication waiver (http://creativeco mmons.org/publicdomain/zero/1.0/) applies to the data made available in this article, unless otherwise stated in a credit line to the data. 
provide. Examples of these include thoracostomies to relieve a tension pneumothorax, the transfusion of blood products to treat ongoing blood loss, and pre-hospital emergency anesthesia (PHEA) to definitively manage the airway or to optimise ventilation. To prevent hypoxia during PHEA, patients are normally pre-oxygenated with a high $\mathrm{FiO}_{2}$ and oxygen administration is continued thereafter [2,3].

Oxygen therapy, however, can result in arterial oxygen levels well in excess of the normal maximum physiological levels, causing excessive formation of reactive oxygen species (ROS) and oxygen free radicals which can cause cellular damage [4]. Furthermore, as oxygen is a vasoactive substance, its administration may have unintended haemodynamic effects, such as coronary and systemic vasoconstriction [5-7]. Previous studies have demonstrated an association between hyperoxia and increased mortality in patients following cardiac arrest, sepsis, stroke and traumatic brain injury (TBI) [8-11].

Pre-hospital oxygen administration to trauma patients is therefore a delicate balance and both hypoxia and hyperoxia should be avoided [12]. Where in-hospital oxygen supplementation is normally guided by arterial blood gas analysis (ABGA), suitable tools to guide oxygen therapy in the pre-hospital setting are largely lacking. As many trauma patients receiving PHEA have injuries making them either more prone to hypoxia, or making them more vulnerable to the consequences of hypoxia, clinicians usually tend to prioritize preventing hypoxia over hyperoxia [2].

It remains unclear how many trauma patients receiving PHEA are exposed to prolonged hyperoxia in the pre-hospital setting. Therefore, the aim of this study was twofold: (1) to investigate the incidence of hyperoxia in trauma patients receiving PHEA in the pre-hospital setting, and (2) to determine factors that may help guide clinicians with pre-hospital oxygen administration in these patients.

\section{Methods}

\section{Study setting and design}

This is a retrospective study of all patients who received PHEA from Air Ambulance Kent Surrey Sussex (AAKSS) between 1 October 2014 and 1 May 2019 and who were subsequently transferred to St George's Hospital (STGH), London. STGH is a designated MTC, providing specialist tertiary care for the South West London and Surrey Trauma Network (SWLSTN), covering a population of approximately 2.6 million. STGH has an on-site helipad and approximately $83 \%$ of patients arriving by the HEMS team are flown in. AAKSS is a HEMS provider, covering three counties in the southeast of England with a resident population of 4.5 million and transient population of up to 8 million. Two doctor/paramedic teams respond in either a helicopter or response car from one base. The service attends approximately 2000 patients per year. Most patients attended by the HEMS service are first seen by a ground ambulance crew and/or a critical care paramedic.

PHEA was carried out according to the AAKSS standard operating procedure (SOP). All patients were preoxygenated with a high $\mathrm{FiO}_{2}$ before rapid sequence induction (RSI). During the study period this was achieved by applying a non-rebreathe mask with $15 \mathrm{~L} /$ min of oxygen $\left(\mathrm{O}_{2}\right)$ for several minutes prior to intubation. When a difficult airway was anticipated, additional apnoeic oxygenation (ApOx) was provided by administering $\mathrm{O}_{2}$ at $15 \mathrm{~L} / \mathrm{min}$ via nasal prongs during the apnoeic phase of intubation. After RSI, intermittent positive pressure ventilation (IPPV) was initiated using a transport ventilator (either Pneupac ParaPAC 310 or Dräger Oxy$\log 3000$ ) until handover in hospital. During the study period there was no SOP for reducing $\mathrm{FiO}_{2}$ based on high oxygen saturations.

A patient deemed to have life-threatening major traumatic haemorrhage is declared 'Code Red' at the discretion of the attending HEMS clinicians. Transfusion therapy consisted of packed red blood cells (PRBC) and freeze-dried plasma (FDP).

\section{Study population}

Patients were deemed eligible if they were 18 years or older, had sustained traumatic injuries, underwent PHEA, and were subsequently transferred to STGH by AAKSS. The initial ABGA had to be performed within 60-min after arrival in STGH. Excluded patients were those $<18$ years, patients who underwent PHEA for medical (i.e. non-traumatic) reasons and patients wherein the first ABGA was performed $>60$ min following admission (to reduce the risk of confounding by in-hospital treatments).

\section{Data acquisition}

The patient population was selected from the AAKSS electronic database (HEMSBase 2.0 Medic One Systems Ltd, UK) using the following criteria: traumatic injuries, completion of pre-hospital PHEA, HEMS as transport mode and STGH as destination hospital. Pre-hospital data abstracted from HEMSBase included: age, gender, mechanism of injury, body regions injured, initial Glasgow Coma Score (GCS), PHEA pre-oxygenation- and apnoeic oxygenation, the occurrence of oxygen desaturations $\left(\mathrm{SpO}_{2}<90 \%\right)$ peri- or post $\mathrm{PHEA}, \mathrm{FiO}_{2}$ post intubation, time from PHEA to presentation in hospital and $\mathrm{SpO}_{2}$ as measured by pulse oximetry just before handover in hospital. 
In-hospital data were obtained from the STGH electronic patient records, and included the first ABGA result in hospital after handover in the Emergency Department (ED). ABGA results were obtained using AQURE, a middleware system used to record and retrieve data from point of care devices.

\section{Clinical endpoints}

The primary endpoint of interest in this study was the incidence of hyperoxemia in the first ABGA performed after handover in the ED. Secondary endpoint of interest was the association of pre-hospital patient- and treatment characteristics with the occurrence of hyperoxemia.

For the purpose of this study, clinically relevant hypoxemia was defined as $\mathrm{PaO}_{2}<8 \mathrm{kPa}$, normoxemia as $\mathrm{PaO}_{2}$ 8-16 kPa, mild hyperoxemia as $\mathrm{PaO}_{2}>16-26.6 \mathrm{kPa}$, and severe hyperoxemia as $>26.6 \mathrm{kPa}[13,14]$.

\section{Ethical considerations}

This project met National Institute for Healthcare Research (NIHR, UK) criteria for service evaluation and formal ethical approval was therefore not required. The project was approved by the AAKSS Research \& Development Committee. A data sharing agreement is in place between AAKSS and STGH.

\section{Statistical analysis}

Descriptive statistics are given as mean $[95 \% \mathrm{CI}]$ or median [IQR]. Comparisons across groups (hypoxemia, normoxemia, mild hyperoxemia and severe hyperoxemia) were made using Fisher exact and Kruskal-Wallis tests, where appropriate. Univariate correlation analysis with calculation of Spearman correlation coefficients was performed to evaluate the association of clinical- and treatment factors with the primary outcome. Multivariable logistic regression analyses were carried out to determine which factors were independently associated with hyperoxemia upon arrival in the major trauma center (MTC). Odds ratios (OR) were calculated for these factors. Missing values are reported in the results section of the manuscript according to the STROBE guideline [15]. A $p$-value $<0.05$ was regarded as statistically significant. All statistical analyses were conducted using SPSS 27.0 for Mac statistical package.

\section{Results}

\section{Patient characteristics}

PHEA was performed in 1241 patients during the study period, 432 patients were subsequently admitted to STGH. 285 fulfilled the inclusion criteria. 76 patients were excluded ( 5 patients were missing arrival times, 36 had missing ABGA results, and 35 patients had missing time of first $A B G A)$. Further results refer to the remaining 147 patients (Fig. 1).

Patient characteristics of the study population are depicted in Table 1. Most patients were male (77\%) and involved in road traffic collisions (RTCs) (46\%). Median GCS at presentation was 8, and a significant proportion of the patients had confirmed TBI upon subsequent investigation at the MTC. $25 \%$ had chest injuries on presentation and $23 \%$ had pre-hospital thoracostomies in addition to PHEA. 17\% were declared 'Code Red' pre-hospital.

\section{Pre-hospital oxygen administration and monitoring}

Oxygen was administered with an $\mathrm{FiO}_{2}$ of 1.0 in all 147 patients after PHEA and during transport, and only adjusted to $\mathrm{FiO}_{2}$ of 0.5 in 3 patients (2\%). Pulse oximetry recordings on the HEMS monitor at the moment of handover in the trauma center were available for 142/147 patients. The median [IQR] $\mathrm{SpO}_{2}$ at handover was 100 [98-100\%]. There were 112 patients (80\%) with an $\mathrm{SpO}_{2}>98 \%, 8$ patients with an $\mathrm{SpO}_{2}$ reading of 95-98\%, and 22 patients with an $\mathrm{SpO}_{2}$ reading $<95 \%$. Information on the quality of the trace was not available. Following arrival in the ED, 27 patients (18\%) were maintained on $\mathrm{FiO}_{2}$ 1.0, whereas oxygen was down-titrated in the remaining patients.

\section{$A B G A$ results}

Median [IQR] (95\% CI) $\mathrm{PaO}_{2}$ in the first ABGA after HEMS handover was 36.7 [18.5-52.2] $\mathrm{kPa}$, with a range of $7.0-86.0 \mathrm{kPa}$. The majority of the patients $(90 / 147$, $61.2 \%)$ had severe hyperoxemia, whereas 30 patients (20.4\%) had mild hyperoxemia, 26 patients (19.7\%) had normoxemia and only 1 patient $(0.7 \%)$ had hypoxemia. Patient and treatment characteristics stratified by $\mathrm{PaO}_{2}$ are represented in Table 1. Patients with (severe) hyperoxemia in their ABGA generally presented to the HEMS team with a higher median GCS before they were intubated, they had less often an oxygen desaturation peri- or post intubation, and had a higher pulse oximetry $\mathrm{SpO}_{2}$ on the HEMS monitor at handover in hospital.

\section{Association of patient characteristics and treatment variables with $\mathrm{PaO}_{2}$}

Univariate correlation coefficients of $\mathrm{PaO}_{2}$ with prehospital patient- and treatment variables are represented in Table $2 . \mathrm{SpO}_{2}$ pulse oximetry readings on the HEMS monitor at handover in hospital showed a positive association with $\mathrm{PaO}_{2}(\mathrm{r}=0.28, p<0.001)$, whilst the occurrence of an oxygen desaturation peri- or post PHEA $(\mathrm{r}=-0.23, p=0.006)$ chest injuries $(\mathrm{r}=-0.22$, $p=0.008$ ) and the treatment of the patient with thoracostomies $(\mathrm{r}=-0.19, p=0.022)$ in the pre-hospital setting 


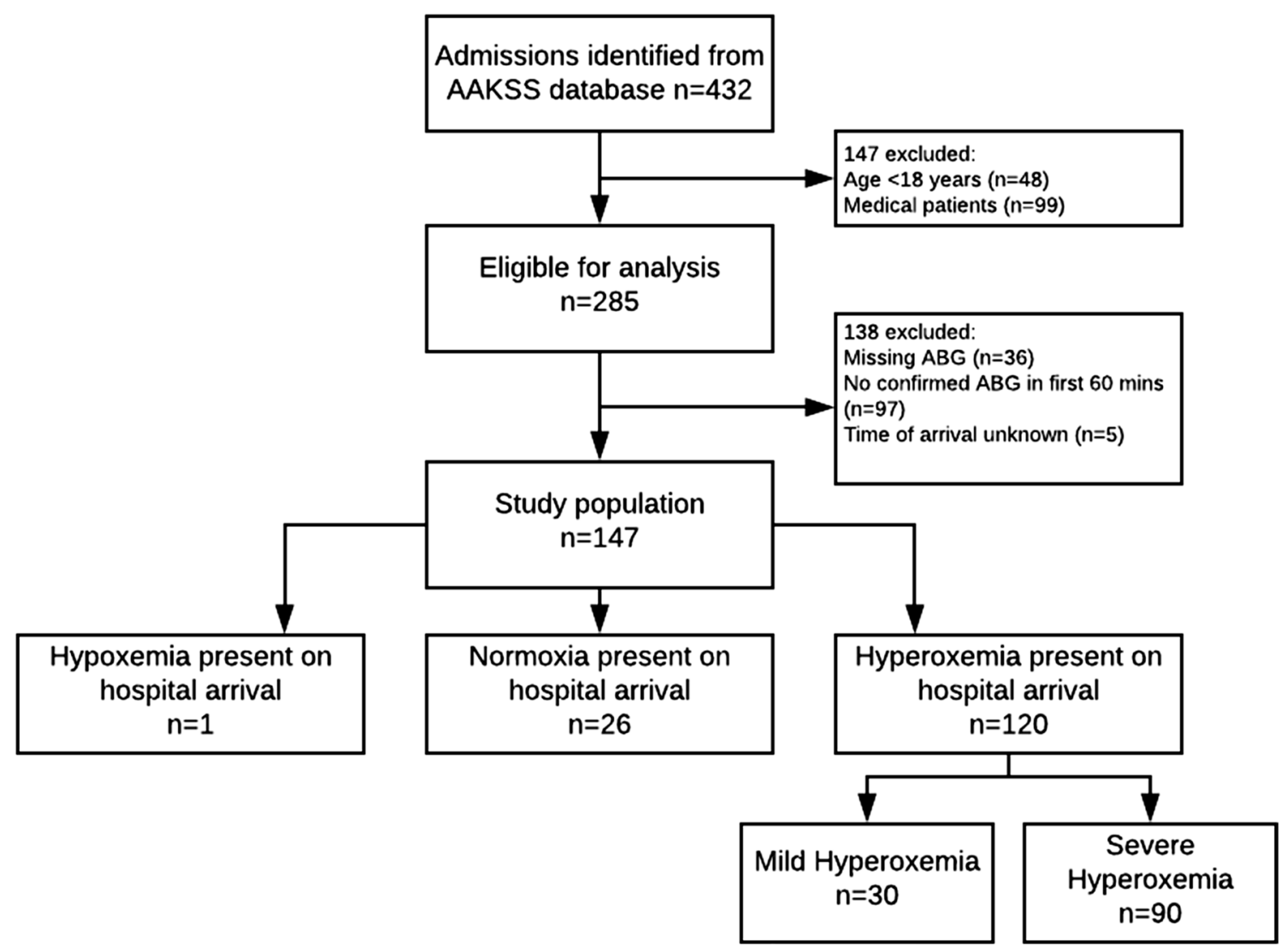

Fig. 1 Derivation of study population. Legend: ABGA, arterial blood gas analysis

were all negatively associated with the occurrence of hyperoxemia.

In multivariate logistic regression analysis, HEMS pulse oximetry $\mathrm{SpO}_{2}$ at handover in hospital remained the only factor independently associated with the presence of hyperoxemia in the ABGA. Odds ratios for the presence of hyperoxemia were dependent on the $\mathrm{SpO}_{2}$ cut-off used (Table 3), but any $\mathrm{SpO}_{2} \geq 97 \%$ was associated with a significantly increased odds of hyperoxia. In total, 113/142 (79.5\%) patients with $\mathrm{SpO}_{2}$ values available presented with an $\mathrm{SpO}_{2} \geq 97 \%$. An $\mathrm{SpO}_{2} \geq 97 \%$ had a sensitivity of 86.7 [79.1-92.4]\%, a specificity of 37.9 [20.7-57.8]\%, a positive predictive value of 84.5 [70.2-87.9]\% and a negative predictive value of 42.3 [27.4-58.7]\% for the presence of hyperoxemia.

\section{Discussion}

In this study, we demonstrate that trauma patients who have undergone PHEA often have a profound hyperoxemia upon arrival in hospital (61-81\%). In the prehospital setting, where ABGA is not readily available, a maximum $\mathrm{SpO}_{2}$ not higher than $97 \%$ may be used as a reasonable goal for $\mathrm{FiO}_{2}$ titration to reduce the chance of (deleterious effects of) tissue hyperoxia [4].

Over the past years, the potential deleterious effects of hyperoxemia have become well known. Oxygen levels well in excess of the maximal physiological levels cause excessive formation of ROS resulting in cellular damage [16]. There is compelling evidence that patients exposed to hyperoxia have an increased risk of both short- and long-term mortality $[17,18]$. This risk is related to both the extent and the duration of hyperoxia patients were exposed to, although recent in-vivo studies have demonstrated that even a short exposure to supra-physiological oxygen levels may result in haemodynamic changes (reduction in cardiac output and an increase in vascular resistance for example) that may contribute to a worse outcome [19].

Prevention of hyperoxemia in trauma patients after PHEA is of the utmost importance, even more so when transport distances to definitive care are long, such as in our population where the average time from PHEA to presentation in hospital was $59 \mathrm{~min}$. However, several factors may prevent early titration of $\mathrm{FiO}_{2}$ by HEMS teams. First, many trauma patients have chest- and 
Table 1 Patient characteristics of the study population stratified by $\mathrm{PaO}_{2}$ in first arterial blood gas analysis after arrival in hospital $(n=147)$

$$
\begin{aligned}
& \text { ALL }(n=147) \quad \text { Hypoxemia }(n=1) \quad \text { Normoxemia }(n=26) \quad \text { Mild Hyperoxemia }(n=30) \begin{array}{l}
\text { Severe } \\
\text { Hyperoxemia }
\end{array} \\
& (n=90)
\end{aligned}
$$

\begin{tabular}{|c|c|c|c|c|c|c|}
\hline \multicolumn{7}{|l|}{ Demographics } \\
\hline Age (years, [IQR]) & $49[30-65]$ & $29[N A]$ & 44 [29-53] & 53 [29-68] & $49[30-66]$ & .59 \\
\hline Male, gender $[n, \%]$ & $116[78.9]$ & $0[0]$ & $23[88.4]$ & $25[83.3]$ & $68[75.5]$ & .21 \\
\hline \multicolumn{7}{|l|}{ Mechanism } \\
\hline $\operatorname{RTC}[n, \%]$ & $66[44.9]$ & $1[100]$ & $12[46.2]$ & $16[53.3]$ & $37[41.1]$ & .45 \\
\hline Falls $[n, \%]$ & $54[36.7]$ & $0[0]$ & $9[34.6]$ & $9[30.0]$ & $36[40.0]$ & \\
\hline Assault [n,\%] & $10[6.8]$ & $0[0]$ & $3[11.5]$ & $3[10]$ & $4[4.4]$ & \\
\hline Intentional self-harm [n,\%] & $9[6.1]$ & $0[0]$ & $1[3.8]$ & $2[6.7]$ & $6[6.6]$ & \\
\hline Accidental injury (other) [n,\%] & $3[2.0]$ & $0[0]$ & $1[3.8]$ & $0[0]$ & $2[2.2]$ & \\
\hline Fire exposure $[n, \%]$ & $3[2.0]$ & $0[0]$ & $0[0]$ & $0[0]$ & $3[3.3]$ & \\
\hline Other & $2[1.4]$ & $0[N A]$ & $0[N A]$ & $0[N A]$ & $2[2.2]$ & \\
\hline \multicolumn{7}{|l|}{ Body regions injured } \\
\hline Head $[n, \%]$ & 118 [80.3] & $1[100]$ & $23[88.5]$ & $22[73.3]$ & $72[80]$ & .52 \\
\hline Chest [n,\%] & 38 [25.9] & $0[0]$ & $10[38.5]$ & $11[36.7]$ & 17 [18.9] & .09 \\
\hline \multicolumn{7}{|l|}{ Vital signs on arrival HEMS } \\
\hline GCS $[\mathrm{QQR}]$ & $8[4-11]$ & $4[\mathrm{NA}]$ & $5[3-9]$ & $9[5-12]$ & $8[5-11]$ & .02 \\
\hline $\mathrm{SpO}_{2}(\%, \mathrm{IQR}]$ & $98[88-100]$ & $98[N A]$ & 92 [88-99] & 98 [98-99] & 98 [88-100] & .63 \\
\hline SBP (mean, 95\%Cl) & 132 [126-138] & $86[\mathrm{NA}]$ & 129 [115-142] & 134 [117-150] & 133 [126-140] & .005 \\
\hline HR (mean, 95\%Cl) & 96 [91-101] & $122[\mathrm{NA}]$ & 104 [92-117] & $97[84-110]$ & 93 [86-99] & .68 \\
\hline \multicolumn{7}{|l|}{ Pre-hospital interventions } \\
\hline \multicolumn{7}{|l|}{ PHEA } \\
\hline Pre-oxygenation [n,\%] & 147 & $1[100]$ & $26[100]$ & 30 [100] & 90 [100] & NA \\
\hline $\mathrm{ApOx}[\mathrm{n}, \%]$ & 2 & $0[\mathrm{NA}]$ & $1[3.8]$ & $1[3.3]$ & $0[0]$ & .35 \\
\hline Peri-Post-PHEA & 56 & $0[\mathrm{NA}]$ & $15[57.7]$ & $14[46.7]$ & $27[30.0]$ & .04 \\
\hline \multicolumn{7}{|l|}{ Desaturation [n,\%] } \\
\hline \multicolumn{7}{|l|}{ Post intubation $\mathrm{FiO}_{2}$} \\
\hline $1.0[n, \%]$ & $144[97.3]$ & $1[0.7]$ & $26[34.6]$ & 28 [30] & $89[28.9]$ & .52 \\
\hline $0.5[n, \%]$ & $3[1.7]$ & $0[0]$ & $0[0]$ & $2[6.7]$ & $1[1.1]$ & \\
\hline Thoracostomies $[\mathrm{n}, \%]^{*}$ & 35 [23.8] & $0[N A]$ & $8[30.8]$ & $11[36.7]$ & $16[17.8]$ & .14 \\
\hline $\begin{array}{l}\text { Transfusion and/or Code Red } \\
{[n, \%]}\end{array}$ & $26[17.7]$ & $0[N A]$ & $6[23.1]$ & $8[26.7]$ & 12 [13.3] & .31 \\
\hline \multicolumn{7}{|l|}{ In-hospital oxygen treatment } \\
\hline $\begin{array}{l}\text { Pulse oximetry } \mathrm{SpO}_{2} \mathrm{HEMS} \\
\text { upon arrival in hospital } \\
(\mathrm{n}=142)\end{array}$ & 100 [98-100] & $76[N A]$ & 98 [95-100] & $100[98-100]$ & 100 [99-100] & .01 \\
\hline \multicolumn{7}{|l|}{$\mathrm{FiO}_{2}$} \\
\hline Maintained at $1.0[n, \%]$ & $26[17.7]$ & $0[0]$ & $6[23.1]$ & $2[6.7]$ & $18[20]$ & .82 \\
\hline Downtitrated (0.8-0.2) & $120[81.6]$ & $1[100]$ & $20[66.9]$ & 28 [93.3] & $71[78.9]$ & \\
\hline Unknown & 1 & 0 & 0 & 0 & $1[1.1]$ & \\
\hline \multicolumn{7}{|l|}{ ABGA results } \\
\hline $\mathrm{PaO}_{2}[$ median, IQR $]$ & $36.7[18.5-52.2]$ & 7.9 [NA] & $13.8[11.1-14.9]$ & $19.5[18.4-23.6]$ & $46.3[39.0-60.8]$ & $<.001$ \\
\hline $\mathrm{PaCO}_{2}[$ median, IQR] & $6.1[5.6-7.0]$ & $9.0[\mathrm{NA}]$ & $6.8[5.9-7.5]$ & $6.3[5.8-7.1]$ & $5.9[5.3-6.5]$ & .016 \\
\hline $\mathrm{pH}[$ median, IQR] & $7.3[7.2-7.4]$ & $7.14[\mathrm{NA}]$ & $7.3[7.2-7.4]$ & $7.3[7.2-7.3]$ & $7.3[7.3-7.4]$ & .002 \\
\hline
\end{tabular}


Table 2 Univariate correlation analysis of in-hospital $\mathrm{PaO}_{2}$ with pre-hospital patient- and treatment factors $(n=147)$

\begin{tabular}{|c|c|c|}
\hline Pre-hospital patient and/or treatment factor & $r$ & $p$ \\
\hline Age & .013 & .87 \\
\hline Sex & .052 & .53 \\
\hline $\mathrm{MOI}$ & .023 & .78 \\
\hline Chest injuries & -.220 & .008 \\
\hline Head and/or CNS injuries & -.003 & .97 \\
\hline Transfusion and/or 'Code Red' & -.146 & .08 \\
\hline Any oxygen desaturation peri-or post PHEA & -.228 & .006 \\
\hline ApOx & -.134 & 0.11 \\
\hline Thoracostomies* & -.190 & .022 \\
\hline HEMS Pulse oximetry $\mathrm{SpO}_{2}$ at handover in hospital & .276 & $<.001$ \\
\hline
\end{tabular}

MOI; Mechanism of Injury, CNS; central nervous system, PHEA; Pre-hospital Emergency Anesthesia, ApOx; Apnoeic oxygenation, $\mathrm{SpO}_{2}$; Oxygen saturation. ${ }^{*}$ unilateral or bilateral

Table 3 Multivariate analysis of treatment variables associated with $\mathrm{PaO}_{2}$

\begin{tabular}{llll}
\hline Variable & OR & $\mathbf{9 5 \%} \mathbf{C l}$ & $\boldsymbol{p}$ \\
\hline PH episode of oxygen desaturation & 0.96 & {$[0.89-1.07]$} & .18 \\
Chest injuries present & 0.52 & {$[0.21-1.26]$} & .29 \\
Thoracostomies* $^{*}$ & 0.69 & {$[0.27-1.74]$} & .11 \\
SpO2 at handover $\geq 93 \%$ & 1.73 & {$[0.56-5.34]$} & .35 \\
SpO2 at handover $\geq 95 \%$ & 2.02 & {$[0.69-5.83]$} & .25 \\
SpO2 at handover $\geq 97 \%$ & 3.99 & {$[1.58-10.08]$} & .001 \\
SpO2 at handover $\geq 99 \%$ & 4.49 & {$[1.85-10.94]$} & $<.001$ \\
\hline
\end{tabular}

$\mathrm{PH}$; pre-hospital, $\mathrm{SpO}_{2}$; Oxygen saturation. *Unilateral or bilateral

central nervous system (CNS) pathology making them both more prone and vulnerable to hypoxic episodes [20]. Most physicians will prefer a period of hyperoxia in these patients above a potential hypoxic episode, and will therefore be reluctant to down-titrate $\mathrm{FiO}_{2}$ at an early stage. Second, effective down-titration may be prevented by the settings of (especially older model) transport ventilators who only have a limited range of $\mathrm{FiO}_{2}$ options. Further, the lack of a clear target for $\mathrm{FiO}_{2}$ titration in the pre-hospital setting may make critical care teams apprehensive to down-titrate $\mathrm{FiO}_{2}$. In-hospital titration is normally done based on $\mathrm{PaO}_{2}$ results from ABGA. Although pre-hospital blood gas analysis has been shown to be feasible [21] and been demonstrated to have the potential to increase pre-hospital diagnostic accuracy [22], there are limitations to its use (e.g. narrow temperature range of operation) and its use is not widespread across critical care services.

In this study, we demonstrate that in the pre-hospital setting, where ABGA is not readily available, a maximum $\mathrm{SpO}_{2}$ not higher than $97 \%$ can be used as a reasonable goal for $\mathrm{FiO}_{2}$ titration to reduce the chance of (deleterious effects of) tissue hyperoxia in intubated trauma patients. These findings are in-line with the recommendations of the British Thoracic Society Guidelines on use of oxygen in emergency settings, advising that oxygen should be administered to reach a target oxygen saturation range of 94-98\% for most critically ill patients [4]. Titration of $\mathrm{FiO}_{2}$ in order to prevent hyperoxia is especially important in trauma patients with TBI undergoing PHEA. A significant proportion of the patients included in our cohort ( $\mathrm{n}=46,22 \%)$ had confirmed TBI on imaging and of these 29 (63\%) were exposed to severe hyperoxia. Previous evidence suggests that patients suffering ischaemic/ reperfusion injuries, such as TBI, are especially sensitive to the adverse effects of hyperoxia. Menzel et al. demonstrated a substantial decrease in cerebral perfusion following hyperoxaemia in TBI patients, mediated via cerebral vasoconstriction, this mechanism may create ischemia and exacerbate injury [23]. Further, in a retrospective review of 1547 patients with severe TBI it was found that both exposure to hyperoxemia and hypoxemia within the first $24 \mathrm{~h}$ of hospitalisation was associated with worse short-term functional outcomes and higher mortality [20].

Pre-hospital critical care teams should not regard supplemental oxygen as a protective therapy for all trauma patients after PHEA. Especially when the risk of hypoxemia is deemed low (e.g. absence of chest injuries, no suspicion of TBI), early down-titration of $\mathrm{FiO}_{2}$ should be considered. Using pulse oximetry $\mathrm{SpO}_{2}$ values in the pre-hospital setting to accomplish this may prevent prolonged periods of hyperoxemia, and resultant deleterious effects.

\section{Limitations}

Our study has several limitations inherent to the retrospective study design. First, we had to rely on the data as provided by the HEMS team. Although there were some missing data, overall data completeness was good due to the use of our electronic patient record with dedicated data entry fields for all patients. Further, we included patients whom received and ABGA within 60-min of arrival to hospital, and in-hospital oxygen therapy adjustments immediately after handover and before the ABGA may have confounded our findings. However, despite that $\mathrm{FiO}_{2}$ down-titrated after handover in 120/147 patients, the vast majority were found to have significant hyperoxemia in the ABGA. Whether this was the result of prolonged hyperoxemia in the pre-hospital setting, inadequate $\mathrm{FiO}_{2}$ down-titration in hospital before the ABGA was performed, or both, could not be established. However, it is likely that our findings reflect a general lack of awareness to prevent hyperoxemia in intubated trauma 
patients. It is important to mention that our findings are not extrapolatable to other (non-trauma) populations, who may have a different $\mathrm{SpO}_{2}$ target based on their presenting pathophysiology. Further, it should be mentioned that $\mathrm{SpO}_{2}$ can only be used to guide oxygen therapy when a reliable pulse oximetry trace is recorded, which often is not the case in patients with significant hypovolemic shock, and in patients with severe hypothermia. Finally, this study was aimed to investigate the incidence of hyperoxemia, and to determine patient factors that may help guide clinicians with pre-hospital oxygen titration in these patients. As we did not collect (patient centered) outcome data, we could not determine any associations between (the degree of) hyperoxemia and outcome.

\section{Conclusion}

Trauma patients who have undergone PHEA often (61-81\%) have a profound hyperoxemia within 60-min of arrival to hospital. In the pre-hospital setting, where ABGA are not readily available, a titrated approach to oxygen therapy should be considered to reduce the incidence of potentially harmful tissue hyperoxia.

\begin{abstract}
Abbreviations
AAKSS: Air Ambulance Kent Surrey Sussex; ABGA: Arterial blood gas analysis; ApOx: Apnoeic Oxygenation; CNS: Central Nervous System; ED: Emergency Department; GCS: Glasgow Coma Score; HEMS: Helicopter Emergency Medical Service; IPPV: Intermittent Positive Pressure Ventilation; KSSAAT: Kent Surrey Sussex Air Ambulance Trust; MOI: Mechanism of Injury; MTC: Major Trauma Centre; NIHR: National Institute for Healthcare Research; OR: Odds Ratio; PHEA: Pre-hospital Emergency Anesthesia; ROS: Reactive oxygen species; RSI: Rapid Sequence Induction; RTCs: Road Traffic Collisions; SOP: Standard Operating Procedure; STGH: St George's Hospital; SWLSTN: South West London and Surrey Trauma Network; TBI: Traumatic Brain Injury.
\end{abstract}

\section{Acknowledgements}

Not applicable.

\section{Authors' contributions}

All authors fulfilled the ICMJE criteria for authorship. AH conceived the study. PL and JG retrieved the data. JG and EtA performed statistical analysis, and EtA drafted the manuscript. RS, AH and RL contributed to the discussion and interpretation of the results. All authors read and approved the final manuscript.

\section{Funding}

Not applicable.

\section{Availability of data and materials}

The datasets used and/or analysed during the current study are available from the corresponding author on reasonable request.

\section{Declarations}

\section{Ethics approval and consent to participate}

This project met National Institute for Healthcare Research (NIHR, UK) criteria for service evaluation and formal ethical approval as well as consent from participants was therefore not required.

\section{Consent for publication}

Not applicable.

\section{Competing interests}

The authors declare that they have no competing interests.

\section{Author details}

${ }^{1}$ University of St Georges, Tooting, London, UK. ${ }^{2}$ Air Ambulance Kent Surrey and Sussex, Hanger 10 Redhill Aerodrome, Redhill RH1 5YP, UK. ${ }^{3}$ University of Surrey, Guildford, UK. ${ }^{4}$ Department of Emergency Medicine, University Medical Center Groningen, Groningen, The Netherlands.

Received: 15 August 2021 Accepted: 3 September 2021

Published online: 10 September 2021

\section{References}

1. National Audit Office. Major trauma care in England: report by the Comptroller and Auditor General. National Audit Office (2010). http://www.nao. org.uk/wp-content/uploads/2010/02/0910213.pdf. Accessed 27 Sept 2017.

2. Braun $P$, Wenzel $V$, Paal P. Anesthesia in prehospital emergencies and in the emergency department. Curr Opin Anaesthesiol. 2010;23(4):500-6.

3. Boulton AJ, Mashru A, Lyon R. Oxygenation strategies prior to and during prehospital emergency anaesthesia in UK HEMS practice (PREOXY survey). Scand J Trauma Resusc Emerg Med. 2020;28(1):99.

4. Society B. Emergency Oxygen|British Thoracic Society|Better lung health for all (2020). https://www.brit-thoracic.org.uk/quality-improvement/ guidelines/emergency-oxygen/. Retrieved from 13 Jan 2020.

5. Sjöberg F, Singer M. The medical use of oxygen: a time for critical reappraisal. J Internal Med. 2013;274(6):505-28. https://doi.org/10.1111/joim. 12139.

6. Asfar P, Singer M, Radermacher P. Understanding the benefits and harms of oxygen therapy. Intensive Care Med. 2015;41(6):1118-21. https://doi. org/10.1007/s00134-015-3670-z.

7. McNulty PH, King N, Scott S, Hartman G, McCann J, Kozak M, et al. Effects of supplemental oxygen administration on coronary blood flow in patients undergoing cardiac catheterization. Am J Physiol Heart Circ Physiol. 2005;288(3):H1057-62.

8. Chu D, Kim L, Young P, Zamiri N, Almenawer S, Jaeschke R, et al. Mortality and morbidity in acutely ill adults treated with liberal versus conservative oxygen therapy (IOTA): a systematic review and meta-analysis. The Lancet. 2018;391(10131):1693-705.

9. Stolmeijer R, Bouma H, Zijlstra J, et al. A systematic review of the effects of hyperoxia in acutely ill patients: should we aim for less? Biomed Res Int. 2018;2018:7841295.

10. Page D, Ablordeppey E, Wessman B, et al. Emergency department hyperoxia is associated with increased mortality in mechanically ventilated patients: a cohort study. Crit Care. 2018;22(1):9.

11. Douin D, Anderson E, Dylla L, et al. Association between hyperoxia, supplemental oxygen, and mortality in critically injured patients. Crit Care Explor. 2021;3(5):e0418.

12. Stephens R, Siegler J, Fuller B. Mechanical ventilation in the prehospital and emergency department environment. Respir Care. 2019;64(5):595-603

13. Page D, Ablordeppey E, Wessman B, Mohr N, Trzeciak S, Kollef M, et al. Emergency department hyperoxia is associated with increased mortality in mechanically ventilated patients: a cohort study. Crit Care. 2018;22(1):1-10. https://doi.org/10.1186/s13054-017-1926-4.

14. de Graaff A, Dongelmans D, Binnekade J, de Jonge E. Clinicians' response to hyperoxia in ventilated patients in a Dutch ICU depends on the level of FiO2. Intensive Care Med. 2010;37(1):46-51. https://doi.org/10.1007/ s00134-010-2025-z.

15. von Elm E, Altman DG, Egger M, Pocock SJ, Gøtzsche PC, Vandenbroucke $J P$. The Strengthening the Reporting of Observational Studies in Epidemiology (STROBE) statement: guidelines for reporting observational studies. The Lancet. 2007;370(9596):1453-7.

16. Trachootham D, Lu W, Ogasawara M, et al. Redox regulation of cell survival. Antioxid Redox Signal. 2008;10(8):1343-74.

17. Hafner S, Beloncle F, Koch A, Radermacher P, Asfar P. Hyperoxia in intensive care, emergency, and peri-operative medicine: Dr. Jekyll or Mr. Hyde? A 2015 update. Ann Intensive Care. 2015;5(1):42. 
18. Helmerhorst H, Arts D, Schultz M, van der Voort P, Abu-Hanna A, de Jonge E, van Westerloo D. Metrics of arterial hyperoxia and associated outcomes in critical care*. Crit Care Med. 2017:45(2):187-95.

19. Boussuges A, Rives S, Marlinge $M$, et al. Hyperoxia during exercise: impact on adenosine plasma levels and hemodynamic data. Front Physiol. 2020;11:97.

20. Brenner M, Stein D, Hu P, Kufera J, Wooford M, Scalea T. Association between early hyperoxia and worse outcomes after traumatic brain injury. Arch Surg. 2012;147(11):1042.

21. Schober P, Bossers S, Krage R, et al. Portable blood (gas) analyzer in a helicopter emergency medical service. Air Med J. 2019;38(4):302-4.
22. Zwisler S, Zincuk Y, Bering $X$, et al. Diagnostic value of prehospital arterial blood gas measurements - a randomised controlled trial. Scand J Trauma Resusc Emerg Med. 2019;27(1):32.

23. Menzel M, Doppenberg E, Zauner A, Soukup J, Reinert M, Clausen T, et al. Cerebral oxygenation in patients after severe head injury. J Neurosurg Anesthesiol. 1999;11(4):240-51.

\section{Publisher's Note}

Springer Nature remains neutral with regard to jurisdictional claims in published maps and institutional affiliations.
Ready to submit your research? Choose BMC and benefit from:

- fast, convenient online submission

- thorough peer review by experienced researchers in your field

- rapid publication on acceptance

- support for research data, including large and complex data types

- gold Open Access which fosters wider collaboration and increased citations

- maximum visibility for your research: over 100M website views per year

At BMC, research is always in progress.

Learn more biomedcentral.com/submissions 